OFFICE OF ENVIRONMENT, SAFETY AND HEALTH

Report on the Oversight Assessment of the Operational Readiness Review for the Replacement Tritium Facility at Savannah River Site

Prepared by:
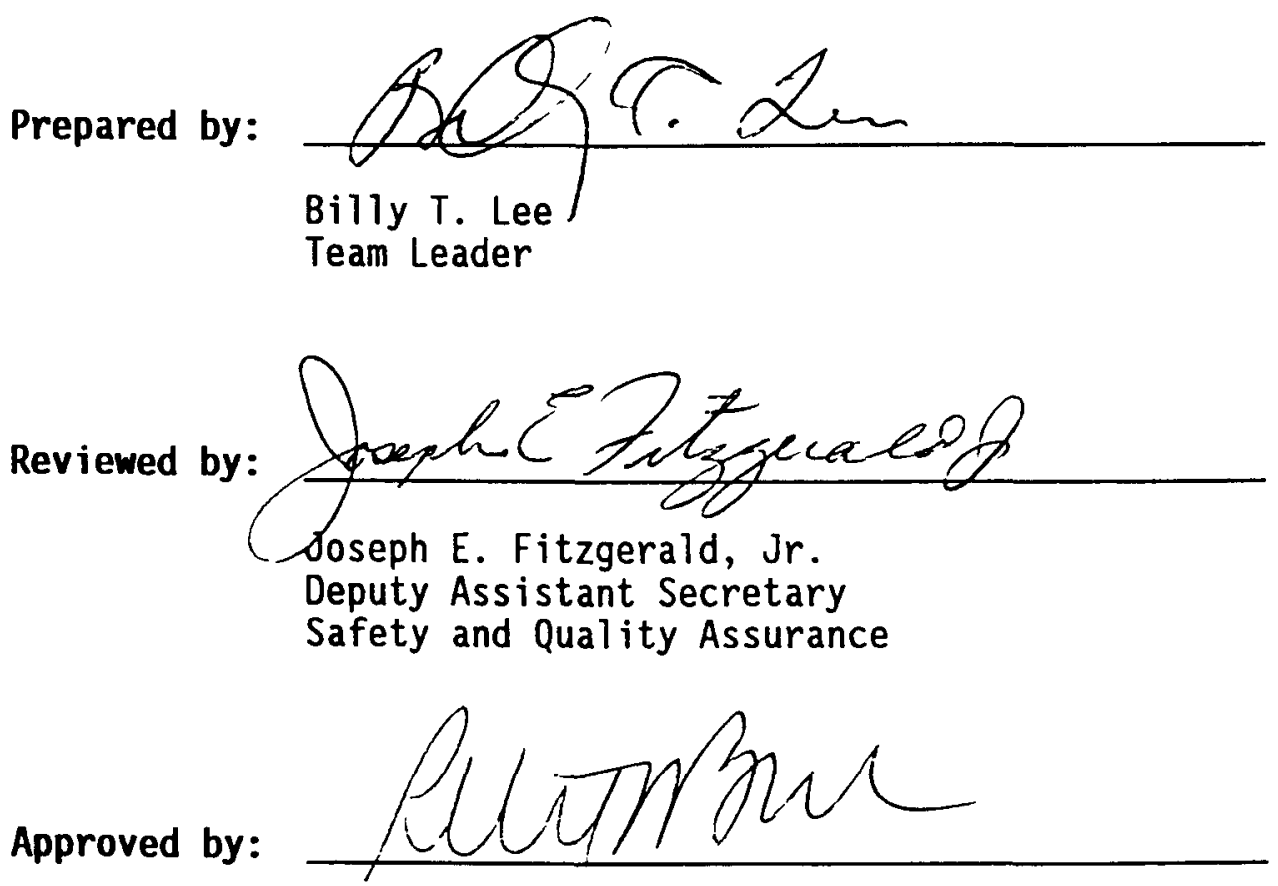

Peter N. Brush

Acting Assistant Secretary

Environment, Safety and Health

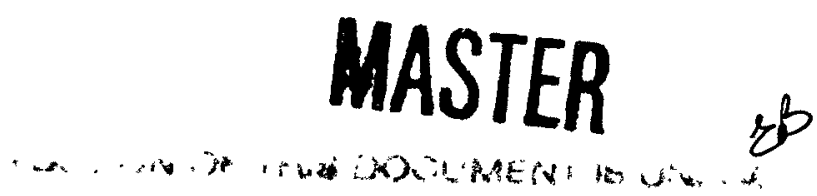




\section{Report of the Oversight Assessment of the Operational Readiness Review of the Replacement Tritium Facility at Savannah River Site}

March 1993

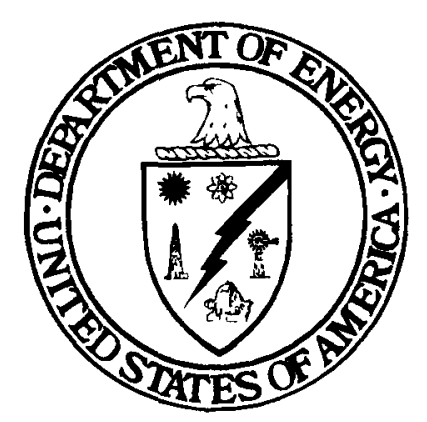

U.S. Department of Energy

Assistant Secretary for Environment, Safety and Health

Washington, D.C. 20585 


\section{DISCLAIMER}

This report was prepared as an account of work sponsored by an agency of the United States Government. Neither the United States Government nor any agency Thereof, nor any of their employees, makes any warranty, express or implied, or assumes any legal liability or responsibility for the accuracy, completeness, or usefulness of any information, apparatus, product, or process disclosed, or represents that its use would not infringe privately owned rights. Reference herein to any specific commercial product, process, or service by trade name, trademark, manufacturer, or otherwise does not necessarily constitute or imply its endorsement, recommendation, or favoring by the United States Government or any agency thereof. The views and opinions of authors expressed herein do not necessarily state or reflect those of the United States Government or any agency thereof. 


\section{DISCLAIMER}

Portions of this document may be illegible in electronic image products. Images are produced from the best available original document. 
CONTENTS

EXECUTIVE SUMMARY . . . . . . . . . . . . . . . . . . . . . . . . . v v

1.0 INTRODUCTION . . . . . . . . . . . . . . . . . . . . . . . . . . . 1

2.0 BACKGROUND . . . . . . . . . . . . . . . . . . . . . . . . . . . . . . . . . 1

3.0 OVERSIGHT PLANNING AND METHODOLOGY . . . . . . . . . . . . . . . . . . . 1

4.0 STANDARDS AND REVIEW CRITERIA . . . . . . . . . . . . . . . . . . . 2

5.0 RESOURCES AND ASSIGNMENTS . . . . . . . . . . . . . . . . . . . . . 3

6.0 ASSESSMENT RESULTS . . . . . . . . . . . . . . . . . . . . . . . . . . 4

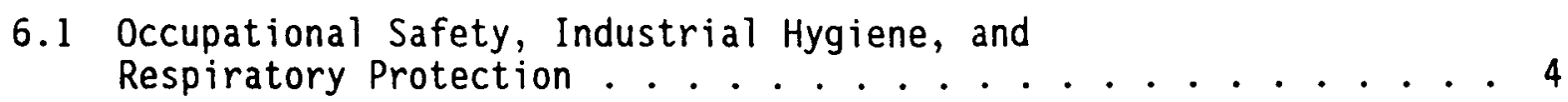

6.2 Fire Protection ...................... 5

6.3 Chemical Safety . . . . . . . . . . . . . . . . . . 7

6.4 DP ORR Effectiveness . . . . . . . . . . . . . . . . 8

7.0 CONCLUSION . . . . . . . . . . . . . . . . . . . . . 11

APPENDIX A. TEAM BIOGRAPHIES . . . . . . . . . . . . . . . . . A - 1

APPENDIX B. EH OBSERVATIONS AND FOLLOWUP ACTIONS . . . . . . . . . . . B - 1 
$$
\text { . }
$$ 


\section{EXECUTIVE SUMMARY}

This report presents the results of an oversight assessment (OA) conducted by the U.S. Department of Energy's (DOE) Office of Environment, Safety and Health (EH) of operational readiness review (ORR) activities for the Replacement Tritium Facility (RTF) located at Savannah River Site (SRS). The EH OA of this facility took place concurrently with an ORR conducted by the DOE Office of Defense Programs (DP). The DP ORR was conducted from January 19 through February 5, 1993. The EH OA was performed in accordance with the protocol and procedures specified in "EH Program for Oversight Assessment of Operational Readiness Evaluations for Startups and Restarts," dated September 15, 1992.

The EH OA Team evaluated the OP ORR to determine whether it was thorough and demonstrated sufficient inquisitiveness to verify that the implementation of programs and procedures adequately ensures the protection of worker safety and health.

The EH OA Team performed its evaluation of the DP ORR in the following technical areas: occupational safety, industrial hygiene, and respiratory protection; fire protection; and chemical safety. In the areas of fire protection and chemical safety, the EH OA Team conducted independent verticalslice reviews to confirm OP ORR results. Within each technical area, the EH $O A$ Team reviewed the DP ORR Plan, including the Criteria Review and Approach Documents (CRADs); the qual ifications of individual DP ORR team members; the performance of planned DP ORR activities; and the results of the DP ORR.

The EH OA Team's overview and vertical-slice reviews confirmed the adequacy of the DP ORR in the above-cited worker safety areas. The EH OA Team agrees with the Findings and Observations identified by the DP ORR Team for these areas and concludes that they represent a complete list and proper categorization as either Findings or Observations. In addition, the EH OA Team identified a number of issues that were subsequently incorporated into the DP ORR review, including (1) lack of a documented pressure safety program, (2) deficiencies in carcinogen control procedures for asbestos-containing materials located in the RTF, and (3) deficiencies in the issuance and control of protective equipment.

The EH OA Team also identified six Observations for strengthening the DP ORR process in the areas of worker safety during future ORRs. These include (1) increasing the specificity of the CRADs; (2) incorporating worker safety into the issue evaluation criteria; (3) increasing the experience of the DP ORR Team in the areas of occupational safety, industrial hygiene, and chemical safety; (4) considering process systems that may pose hazards to workers; (5) restructuring the organization and assignment of responsibilities for worker safety areas; and (6) revising the DP ORR report structure to reflect the actual facility status at the time the DP ORR is conducted.

Based on this OA, the EH OA Team believes that the startup of the RTF can begin safely, pending satisfactory resolution and verification of closure of (1) the Findings identified in the DP ORR, (2) the open Findings from the Westinghouse Savannah River Company (WSRC) ORR, and (3) startup items currently tracked and scheduled by WSRC. 


\subsection{INTRODUCTION}

A Secretary of Energy Notice issued in 1991 (SEN-16B-91) requires approval from the Secretary before startup of a major new nuclear facility and assigns responsibility for performing an independent oversight review of major startup activities for such facilities to the Department of Energy's (DOE) Office of Environment, Safety and Health (EH). EH is responsible for providing the results of these reviews to the cognizant Program Secretarial Officer for resolution and for making recommendations to the Secretary regarding facility startup.

\subsection{BACKGROUND}

The Replacement Tritium Facility (RTF) at the Savannah River Site (SRS) is operated by the Westinghouse Savannah River Company (WSRC) for the DOE Office of Defense Programs (DP). The RTF Building, a l-acre underground complex, replaces the 234-H tritium loading and unloading facilities. It is designed to reduce tritium emissions and impacts to the environment, to enhance the security of tritium loading and unloading operations, and to meet forecast production rates. When the facility is operational, tritium will be unloaded from old components, purified and enriched, supplemented by tritium from SRS reactors, and loaded into new or reclaimed reservoirs. The RTF incorporates state-of-the-art technology to ensure that a safe and efficient supply of tritium will be available for use into the twenty-first century.

DP conducted an operational readiness review (ORR) of the RTF from January 19 through February 5, 1993. The purpose of the DP ORR was to verify RTF's readiness for startup and the safe introduction of tritium by evaluating whether WSRC and the DOE Savannah River Field Office (SR) have programs, procedures, and controls in place to ensure safe operation of the facility.

\subsection{OVERSIGHT PLANNING AND METHODOLOGY}

DP conducted its ORR of RTF after completion of an ORR performed by WSRC. On the basis of its ORR, WSRC determined that all required programs had been implemented and that RTF was ready for review by line management (i.e., DP). SR concurred with the WSRC evaluation. The objectives of the DP ORR were (1) to determine the adequacy of the WSRC ORR and (2) to make recommendations to the Assistant Secretary for Defense Programs regarding RTF's readiness to operate.

The EH Oversight Assessment (OA) Team evaluated the RTF's readiness for startup using the protocol and procedures specified in the "EH Program for Oversight Assessment of Operational Readiness Evaluations for Startups and Restarts," dated September 15, 1992, and in the EH OA PIan for the DP ORR of the RTF. The EH OA Plan organized the EH OA review into the following worker safety areas: occupational safety, industrial hygiene, and respiratory protection; fire protection; and chemical safety. The EH OA Team performed the following activities with respect to these technical areas:

- The EH Team reviewed the DP ORR PIan ("Department of Energy Headquarters Procedure for an Operational Readiness Review of the Savannah River Site 
Replacement Tritium Facility 233-H," dated December 31, 1992) to determine whether acceptance criteria for the Criteria Review and Approach Documents (CRADS), including their bases and attendant review approaches, were adequate to assess the facility's state of readiness in each worker safety area.

- Qualifications of DP ORR team members were evaluated to determine whether these individuals were capable of providing effective assessment of the facility's state of readiness with respect to specific ORR worker safety areas.

- The DP ORR Team's activities were observed to evaluate whether the quality, depth, and formality of its review were adequate to determine the RTF's state of readiness with respect to assigned worker safety areas.

- Documented DP ORR Findings and Observations were evaluated to determine whether they adequately described deficiencies and whether deficiencies were appropriately characterized as either findings (requiring resolution before startup) or Observations (requiring resolution after startup).

The EH OA Team also selected several areas for conducting limited verticalslice reviews to provide added assurance to develop a conclusion, or to verify a DP ORR conclusion, regarding these areas. Selections for these verticalslice reviews were based primarily on (1) determinations of potential weaknesses in the DP ORR or (2) efforts to validate DP ORR activities.

Deficiencies noted by the EH OA Team were characterized as either Findings (requiring resolution before startup) or observations (requiring resolution after startup) in accordance with DP ORR terminology. The EH OA Team did not designate separate EH OA Findings or Observations for deficiencies identified by the DP ORR Team.

\subsection{STANDARDS AND REVIEW CRITERIA}

The standards and review criteria used by the EH OA were based on the protocol and procedures specified in "EH Program for Oversight Assessment of Operational Readiness Evaluations for Startups and Restarts," dated September 15, 1992, and in the EH OA Plan for the DP ORR of the RTF. The standards and review criteria applicable to this assessment include the following:

- Evaluation of ORR plans and reports for assessment of occupational safety, industrial hygiene, and respiratory protection; fire protection; and chemical safety, including:

- the WSRC ORR PI an and reports; and

- the DOE Headquarters DP ORR Plan for the RTF. 
- Verification of the quality, depth, and formality of the DP ORR evaluation of worker safety and health issues relative to:

- qualifications of the OP ORR Team in the above-cited worker safety areas;

- the DP ORR review process;

- development of DP ORR Findings and Observations; and

- resolution of DP ORR issues with WSRC and SR.

- Verification that the DP ORR Team adequately reviewed programs, procedures, and implementation.

Although the EH OA did not include an independent Order compliance review, it did confirm that applicable DOE Orders were included in the DP ORR review of the occupational safety, industrial hygiene, respiratory protection, fire protection, and chemical safety technical areas. In addition, the $E H O A$ referred to appropriate DOE Orders and worker safety and health protection requirements in its vertical-slice reviews. The Orders referenced included (1) DOE 5483.1A, "Occupational Safety and Health Program for DOE Contractor Employees at Government-Owned Contractor-Operated Facilities, " issued June 22, 1983; (2) DOE 5480.1B, "Environmental Protection, Safety, and Health Program for Department of Energy Operations," issued September 23, 1986;

(3) DOE 5480.4, "Environmental Protection, Safety, and Heaith Protection Standards," issued May 15, 1984; (4) DOE 5480.7, "Fire Protection," issued November 16, 1987; and (5) DOE 5480.10, "Contractor Industrial Hygiene Program," issued June 26, 1985.

\subsection{RESOURCES AND ASSIGNMENTS}

The EH OA Team assessed the effectiveness of the DP ORR of the RTF using a team of specialists led by a senior staff member from the Office of the Assistant Secretary for Safety and Quality Assurance (EH-30). Team members and their areas of review are listed below. Team biographies are provided in Appendix A.

\begin{tabular}{||l|l|}
\hline \hline Team Leader & Billy T. Lee (EH-32.1) \\
\hline Senior Safety Advisor & John A. 0lshinski (Consultant) \\
\hline Occupational Safety & Ronald E. Alexander (Consultant) \\
\hline $\begin{array}{l}\text { Industrial Hygiene and } \\
\text { Respiratory Protection }\end{array}$ & Linda F. Munson (Consultant) \\
\hline Fire Protection & Dennis J. Kubicki (EH-31.3) \\
\hline Chemical Safety & James E. Hard (Consultant) \\
\hline
\end{tabular}




\subsection{ASSESSMENT RESULTS}

\subsection{Occupational Safety, Industrial Hygiene, and Respiratory Protection}

The EH OA Team evaluated the DP ORR Plan, including the CRADs, and the qualifications of DP ORR team members who conducted reviews in the areas of occupational safety and industrial hygiene. The EH OA Team accompanied the DP ORR Team during walkthrough inspections, interviews, and activities related to an emergency drill. The EH OA Team also performed independent reviews and walkthroughs to facilitate its evaluation of DP ORR activities.

In addition, the EH OA Team conducted a review of pertinent RTF site documents, including the RTF Final Safety Analysis Report (FSAR), the WSRC Industrial Hygiene Program Manual, the WSRC Industrial Safety Program Manual, the DOE Safety Evaluation Report, the RTF Startup Plan, the WSRC RTF ORR, a draft health hazard inventory, RTF hazard abatement measurements, and the WSRC RTF DOE Order Compliance Assessment. Selected lower tier site documents (e.g., work packages and operating procedures) were also reviewed.

DP ORR reviewers for the occupational safety and industrial hygiene technical areas were primarily assigned to the Engineering and Technical Support Subteam. Occupational safety and industrial hygiene programs were addressed, or partially addressed, by a number of CRAD criteria. These criteria spanned a variety of technical support disciplines such as training, maintenance, waste management, environmental protection, radiological protection and health physics, emergency preparedness, fire protection, quality assurance, and engineering. The diffusion of occupational safety and industrial hygiene responsibilities over several CRAD criteria and technical support disciplines may have contributed to the fact that certain issues were not initially evaluated by the DP ORR. This issue is discussed further in Section 6.4 , "DP ORR Effectiveness."

The principal DP ORR reviewer for occupational safety and industrial hygiene had less than 2 years of experience with DOE and did not have day-to-day oversight responsibility or specific training in occupational safety or industrial hygiene. This reviewer had been trained as a nuclear engineer and had significant experience in the commercial nuclear industry and with the U.S. Nuclear Regulatory Commission (NRC). He demonstrated his knowledge of several occupational safety and industrial hygiene issues being reviewed, and he was sometimes assisted by other OP ORR team members with specialized occupational safety and industrial hygiene backgrounds. This same person also had review responsibility for chemical safety and a variety of other technical support disciplines. Given the heavy workload and the variety of technical disciplines and review criteria involved, this individual conducted his activities competently and effectively. However, the effectiveness of the DP ORR process would have been enhanced by the assignment of personnel with stronger backgrounds and more experience in the occupational safety and industrial hygiene technical areas. This issue is discussed further in Section 6.4, "DP ORR Effectiveness."

The DP ORR Team identified Findings related to (1) RTF exit doors that do not meet design-basis tornado requirements; (2) lack of an approved workplace 
hazards monitoring plan; (3) deficiencies in accountability during emergency response drills; and (4) lack of compliance with DOE 5483.1A, "Occupational Safety and Health Program for DOE Contractor Employees at Government-Owned Contractor-Operated Facilities," in the areas of workplace monitoring, hazard assessments, and staffing of industrial hygiene technicians. The DP ORR Team al so identified Observations involving (1) the control and issuance of industrial hygiene and personnel protective equipment, (2) carcinogen control procedure deficiencies, (3) lack of a defined pressure safety program, and (4) deficiencies in current hazard assessments related to confined spaces and high-pressure systems. The EH OA Team agrees with DP ORR Findings and Observations in this area.

The EH OA Team observed an RTF emergency response drill that included response to an incipient fire, which then evolved into a scenario including a personnel injury and a major fire in a tritiated atmosphere. The EH OA Team noted that both the injured party and the person performing the rescue wore plastic suits and that neither wore safety harnesses. The EH OA Team questioned whether such personnel protective equipment was appropriate for rescues performed under these conditions. WSRC's investigation of this matter revealed a conflict between WSRC internal procedures (i.e., one procedure precludes use of plastic suits for rescue or firefighting, whereas other procedures and training would have allowed plastic suits for this application). WSRC is subsequently modifying its procedures and training to specify (1) that plastic suits would be authorized for using a fire extinguisher for an incipient fire and (2) that safety harnesses would be used with plastic suits for rescue purposes. In addition, the revised procedures and training will prohibit use of plastic suits in situations involving more than an incipient fire or where there is an Immediately Dangerous to Life or Health (IDLH) environment. The EH OA Team agrees with this approach.

The EH OA overview of the DP ORR confirmed the adequacy of its review of occupational safety, industrial hygiene, and respiratory protection. EH $O A$ Observations related to improving the effectiveness of the DP ORR process during future reviews are discussed in Section 6.4, "DP ORR Effectiveness."

\subsection{Fire Protection}

The EH OA Team evaluated the DP ORR Plan, including the CRADs, and the qualifications of the DP ORR reviewer responsible for fire protection. In addition, the EH OA Team examined RTF documents related to fire safety, including the RTF FSAR, fire hazard control procedures, fire protection system testing and maintenance procedures, and fire department operating procedures and pre-plans. The EH OA Team also reviewed sections of the draft DP ORR report related to fire protection and interviewed the DP ORR fire protection engineer, as well as SR and WSRC fire safety professionals, about the DP ORR review methodology, fire protection design philosophy, firefighting strategies, hazard control efforts, testing and maintenance plans, and hazard analysis techniques. In addition, the EH OA Team conducted facility walkthroughs to identify fire hazards, fire protection features, and the physical configuration and features of the RTF. Finally, the EH OA Team observed the conduct and critique of an emergency drill involving a fire and a personnel injury that occurred inside Building $233-\mathrm{H}$. 
The DP ORR Team (1) evaluated critical fire protection features within the facility; (2) reviewed program documents, policies, procedures, and testing and maintenance records; (3) evaluated an emergency response exercise; and (4) interviewed the fire protection specialists, engineers, and managers who are responsible for fire safety at WSRC and SR.

The DP ORR reviewer for fire safety was technically proficient, thorough, and diligent in the pursuit of identified issues. He acted conservatively in his application of fire protection engineering principles, developing his issues on the basis of "best management practices" as well as DOE fire safety criteria.

The DP ORR Team identified fire protection-related Findings in 1 ife safety systems involving (1) emergency lighting and (2) the inability to use some stairwell exit doors under certain ventilation lineups. The DP ORR also identified Observations related to (1) inadequacies with the draft Fire Hazards Analysis, (2) a Maximum Potential Fire Loss limit that does not meet the DOE Fire Protection Order, and (3) lack of documentation for certain RTF fire seal configurations. The EH OA Team agrees with DP ORR conclusions in these areas.

The EH OA Team performed a limited review of the entire RTF Fire Protection Program. In addition, vertical-slice evaluations of selected aspects of the program were performed in the areas of (1) sprinkler system design,

(2) acceptance testing of fire protection systems, (3) management of fire safety issues, and (4) fire department operations in tritium areas.

During facility walkthroughs, the EH OA Team noted a number of "minor" deviations from fire protection standards, including obstructed sprinkler heads and incomplete fire barrier seals. These deviations had al ready been identified by WSRC and are being tracked to resolution. The EH OA Team considers this systematic approach to the identification, tracking, and resolution of deficiencies to be acceptable.

With respect to the Emergency Preparedness Program, one Finding identified by the DP ORR, and confirmed by the EH OA, noted that fire department and health protection procedures would significantly restrict the site fire department's emergency response within Building $233-\mathrm{H}$ in the event of a tritium release. Such restrictions were confirmed by both the DP ORR and the EH OA during an emergency response exercise conducted at RTF. This issue will be resolved in accordance with procedures established by DP.

The EH OA Team also noted that the current revision of the FSAR does not accurately reflect certain fire protection features (e.g., the design of fire detectors and certain fire barriers). These deficiencies have been acknowledged by WSRC and will be corrected in the next FSAR revision. The EH $O A$ Team considers this response to be acceptable.

The EH OA Team determined that the RTF currently has a fire protection program that encompasses all aspects of fire safety. Elements of this program are still under development or are being implemented. When tritium is introduced into the facility, however, this program will be in place to a degree 
sufficient to provide reasonable assurance that a fire will not cause unacceptable consequences. The EH OA Team reached this conclusion based on (1) the physical fire protection features installed in the facility; (2) the documented fire protection program, including fire protection procedures; and (3) the capabilities of the site emergency response force, which includes a fully trained and equipped fire department as well as medical and utility support groups.

The adequacy of the DP ORR in the area of fire protection was confirmed by the EH OA through (1) its overview of the DP ORR, (2) its review of the RTF Fire Protection Program, and (3) the results of its vertical-slice reviews. EH OA Observations related to improving the effectiveness of the DP ORR process during future reviews are discussed in Section 6.4, "DP ORR Effectiveness."

\subsection{Chemical Safety}

The EH OA Team evaluated the DP ORR procedure, including the CRADs and qualifications of the DP ORR reviewer for chemical safety. In addition, the EH OA Team interviewed the DP ORR reviewer and WSRC personnel responsible for chemical safety and conducted walkthroughs to assess potential chemical safety hazards internal and external to the RTF facility.

The EH OA Team also conducted a review of documents related to chemical safety, including an EH Task Group report (DOE/EH-0282, "Oversight of Chemical Safety at DOE Facilities," dated November 1, 1992); a sampling of Material Safety Data Sheets (MSDSs) applicable to the RTF; a sampling of Preoperational Process Hazard Reviews (PPHRs) prepared for the RTF; hazardous material listings; and RTF procedures for handling chemicals.

The scope of activities for the DP ORR included review of hazardous materials listings; review of operating procedures, including chemical handling procedures in the Industrial Hygiene Program Manual, RTF training plans, and job hazard analyses; walkthroughs of chemical handling and storage areas; and interviews with various facility and site personnel.

The DP ORR reviewer responsible for chemical safety did not have academic credentials or experience in that specific area. The reviewer did, however, have significant experience in the commercial nuclear industry and as a reactor engineer and senior resident inspector for NRC. This same individual had also been assigned principal responsibility for reviewing the occupational safety and industrial hygiene technical areas. Despite the heavy workload, this DP ORR reviewer conducted his activities competently and effectively. However, the effectiveness of the OP ORR process would have been enhanced by the assignment of personnel with chemical safety experience. This issue is discussed further in Section 6.4, "DP ORR Effectiveness."

The DP ORR evaluation of chemical safety was encompassed by one CRAD (i.e., Criterion H.2.3.3, "Hazardous Materials, Transient Combustibles, and Ignition Sources are Adequately Controlled"). The lack of more detailed criteria or subcriteria to assess the various worker safety areas is discussed further in Section 6.4, "DP ORR Effectiveness." 
The DP ORR produced no Findings in the chemical safety area. The one Observation identified by the DP ORR Team involved deficiencies in the chemical control/inventory program. The EH OA Team agrees with these conclusions.

The EH $O A$ Team performed an independent vertical-slice assessment to identify potential chemical hazards external to the RTF. The vertical slice was performed because the DP ORR Team had not conducted a review of this potential hazard. This EH OA activity included a walkthrough of the RTF area and discussions with cognizant WSRC personnel concerning control of hazardous chemicals on site. The EH OA Team found no significant chemical sources external to the RTF that could pose significant risk to that facility.

Another vertical-slice assessment performed by the EH OA Team focused on the PPHRs for RTF. This assessment was conducted because the DP ORR Team did not review the PPHRs, which are controlled administratively using corporate-level guidance found in WSRC-IM-90-135, SRS Process Safety Manual, and at the facility level through such procedures as SOP-PP-233-10012, "RTF Process Safety Management." The PPHRs are required to "identify and evaluate the hazards associated with [new] processes." At the RTF, 21 PPHRs have been completed, which in turn have resulted in about 70 action items (to be completed before startup) and approximately the same number of recommendations (to be completed on a lower priority level as time permits). An EH OA review of eight PPHRs indicated that indepth analyses were performed to generate lists of action items and recommendations. The current lists indicate that 15 action items must still be completed before tritium loading can be accomplished at RTF. A tracking system has been established for these actions and recommendations, and a PPHR Coordinator is responsible for ensuring that the system is kept up to date. The EH OA Team's review of the PPHRs, the action items and recommendations, and the current status of the tracking system indicates that the facility program for PPHRs is acceptable to support facility startup.

The EH OA Team's overview and vertical-slice reviews confirmed the adequacy of the DP ORR in the chemical safety technical area. EH OA Observations related to improving the effectiveness of the DP ORR process during future reviews are discussed in Section 6.4, "DP ORR Effectiveness."

\subsection{DP ORR Effectiveness}

The EH OA review of the effectiveness of the DP ORR was based on review of the DP ORR Plan, qualifications of members of the DP ORR Team, and the methodology and implementation of the DP ORR. In addition, members of the EH OA Team accompanied the DP ORR Team during document reviews, interviews, facility walkthroughs, and observation of RTF emergency drills; attended DP ORR team meetings; and observed resolution of DP ORR-identified issues. The EH OA Team also reviewed the DP ORR report to determine whether it accurately reflected DP ORR activities, Findings, and observations. As previously discussed, the EH $O A$ Team also conducted limited vertical-slice reviews in the areas of fire protection and chemical safety to provide added assurance that would allow the EH OA Team to develop a conclusion, or to verify a OP ORR conclusion, regarding these areas. 
The $E H O A$ overview and vertical-slice reviews resulted in the identification of a number of issues that were not addressed by the DP ORR, in particular (1) lack of a documented pressure safety program at RTF, (2) deficiencies in carcinogen control procedures for asbestos-containing materials located in the RTF, and (3) deficiencies in the issuance and control of protective equipment. The EH OA Team brought these issues to the attention of the DP ORR Team Leader, and they were subsequently incorporated into the DP ORR. The EH OA Team agrees with DP ORR Observations related to these issues.

Although the EH $O A$ overview and vertical-slice reviews confirmed the general adequacy of the DP ORR, as well as the DP ORR Team's conclusions relative to the EH areas, the EH OA Team identified potential improvements to the DP ORR process during future reviews. The CRADs for the EH areas were very broad and lacked specificity. Consequently, the comprehensiveness of the DP ORR Team's review in a particular area was dependent on the experience of individual members of the DP ORR Team, or as discussed above, certain issues were brought to the attention of the DP ORR Team by the EH OA Team.

For example, in the fire protection area, the pertinent CRAD criteria are (1) H.2.3.3, "Hazardous Materials, Transient Combustibles, and Ignition Sources are Adequately Controlled," and (2) M.7.11.1, "Written Policies and Procedures Covering Fire Safety [that] have been Issued.. . in Compliance with DOE Order 5480.7." These criteria do not include important fire protection features such as fire alarms and suppression systems. In addition, the only review guidance provided for the DP ORR relative to physical fire protection systems was to "make a general survey of RTF fire equipment."

In the occupational safety, industrial hygiene, and chemical safety technical areas, the single CRAD criterion dealing with chemical safety is H.2.3.3, "Hazardous Materials, Transient Combustible, and Ignition Sources are Adequately Controlled." The criterion was so general that it did not result in identification of asbestos-containing gaskets used in the RTF, nor did it lead the DP ORR Team to review the PPHRs for the RTF.

Observation EHOA-SRS-RTF-01: The CRADs lack specificity in the worker safety areas.

The EH OA Team's review of the DP ORR Plan indicated that Appendix E, "Issue Evaluation Criteria," which provides guidance to the DP ORR Team for evaluating whether an issue must be corrected before startup, did not include any prioritization or screening criteria for worker safety issues. This deficiency was discussed with the DP ORR Team Leader, who in turn indicated that worker safety would be appropriately considered in the issue prioritization process. An EH OA review of the DP ORR issue disposition process confirmed that RTF worker safety issues were appropriately prioritized. Issue evaluation criteria for DP ORRs, however, should be revised to include prioritization of worker safety issues during future reviews.

Observation EHOA-SRS-RTF-02: Issue evaluation criteria for the DP ORR did not include consideration of matters related to worker safety. 
The DP ORR reviewer responsible for the occupational safety, industrial hygiene, and chemical safety technical areas did not have specific experience in any of these specializations. When combined with the lack of specificity in the CRADs and the heavy workload assigned to this reviewer, the lack of experience may have contributed to the DP ORR Team's initial failure to conduct evaluations of the pressure control program, the control of asbestos materials, and the issuance and control of protective equipment. In addition, this lack of experience may have contributed to the failure to evaluate the PPHRs for RTF or to review DOE/EH-0282, "Oversight of Chemical Safety at DOE Facilities."

Observation EHOA-SRS-RTF-03: The DP ORR specific experience in occupational safety, industrial hygiene, and chemical safety technical areas should be strengthened.

The EH $O A$ review of the DP ORR Plan indicated a general hardware focus on "safety systems," which generally include systems necessary for nuclear safety considerations. However, the plan did not generally include other systems (e.g., process systems) that may pose worker safety hazards.

Observation EHOA-SRS-RTF-04: The CRADs may not adequately consider process systems that may pose hazards to workers.

The $E H O A$ review of the DP ORR indicated that the current structure of the DP ORR Plan and the organization and assignment of responsibilities during the RTF DP ORR may have contributed to the failure to address a number of worker safety issues. For example, certain aspects of occupational safety and industrial hygiene were distributed between several primary and supporting CRADs. In addition, a single DP ORR reviewer had responsibility for evaluating the occupational safety, industrial hygiene, and chemical safety technical areas. This combination of factors may have contributed to failure to review some pertinent documents related to chemical hazards (e.g., DOE/EH-0282, "Oversight of Chemical Safety at DOE Facilities," and the RTF Safety Evaluation Report). In addition, the DP ORR did not evaluate any of the 21 RTF PPHRs as part of its assessment and did not review a number of occupational safety and industrial hygiene issues until they had been identified by the EH OA Team. These issues included (1) pressure safety, asbestos control, and (3) issuance and control of protective equipment.

Observation EHOA-SRS-RTF-05: The organization of the DP ORR and the assignment of responsibilities contributed to weaknesses in the review of issues related to worker safety.

The EH OA review of the implementation of the DP ORR indicated that issues, Findings, and Observations identified by the DP ORR Team would not be reflected in the DP ORR report if those issues were corrected and verified by the DP ORR Team as closed during the course of its review. As a result, the DP ORR report does not truly reflect facility status at the time of the review. In addition, this approach reduces the value of the report as a source of lessons learned with respect to future facility startups and restarts. 
Observation EHOA-SRS-RTF-06: The DP ORR report does not reflect actual facility status at the time of the review.

\subsection{CONCLUSION}

The EH OA Team determined that the DP ORR was conducted in a generally thorough and comprehensive manner in the worker safety areas, inciuding occupational safety, industrial hygiene, respiratory protection, fire protection, and chemical safety. The EH OA Team agrees with the DP ORR Findings and Observations in these areas and concludes that they represent a complete list and proper categorization as either Findings or observations.

In addition, the EH OA Team identified six Observations related to strengthening the DP ORR process in the worker safety areas during future reviews. (EH OA Observations are listed in Appendix B.)

The EH OA Team concludes that the DP ORR, as supplemented by the EH OA vertical-slice reviews, provides an adequate basis for approving the startup of the RTF, pending satisfactory resolution and verification of closure of (1) DP ORR Findings, (2) the open Findings from the WSRC ORR, and (3) startup items currently tracked and scheduled by WSRC. (EH followup activities are listed in Appendix B.) 
APPENDIX A

TEAM BIOGRAPHIES

A - 1 

NAME: Billy T. Lee

AREA OF RESP: Team Leader

ASSOCIATION: Office of Environment, Safety and Health, Headquarters, Department of Energy

EXPERIENCE: $\quad 30$ years

- U.S. Department of Energy

- EH Operations Manager for Savannah River Site

- Team Leader for EH Oversight Assessment

- Participant in several DOE Technical Safety Appraisals

- U.S. National Institute of Standards and Technology

- Research Fire Protection Engineer

- U.S. Naval Facilities Engineering Command

- Fire Protection Engineer

- SRI International and U.S. Naval Radiological Defense Laboratory

- Chemical Engineer

EDUCATION: M.S., Mechanical Engineering, University of Santa Clara

B.S., Chemical Engineering, University of California, Berkeley

OTHER: Professional Fire Protection Engineer, State of California 
NAME: John A. 01 shinski

AREA OF RESP: Senior Safety Expert

ASSOCIATION: Nuclear Engineers and Consuitants, Inc.

EXPERIENCE: $\quad 25$ years

- Nuclear Engineers and Consultants, Inc., President and Chief

Executive Officer

- Provides expert support to the Department of Energy on occupational safety and nuclear safety matters.

- Provides expert testimony related to nuclear safety and nuclear regulatory matters.

- Nuclear Energy Consultants, Inc., General Manager

- Provides expert support to the commercial utility industry on nuclear safety and nuclear regulatory matters.

- Provides expert testimony related to nuclear safety and nuclear regulatory matters.

- U.S. Nuclear Regulatory Commission, Deputy Regional Administrator, Atlanta, GA

- Directed and managed NRC inspection program for 10 Southeastern States, including over 30 operating nuclear reactors and fuel facilities.

- Chairman of NRC Region II Systematic Assessment of Licensee Performance (SALP) Board.

- Chairman of NRC Region II Enforcement Panels.

- U.S. Nuclear Regulatory Commission, Washington, DC

- Chief: Operating Reactors Assessment Branch

- Technical Assistant to Director of Licensing

- Senior Reactor Systems Engineer

- U.S. Navy

- Captain: Naval Reserve Engineering Duty Officer Program

- Chief Engineer, Reactor Controls Officer, Electrical Officer, Main Propulsion Assistant: Naval Nuclear Propulsion Program

EDUCATION: M.S., Management, Duke University

B.S., Mathematics, University of North Carolina 
NAME: $\quad$ Ronald E. Alexander

AREA OF RESP: Occupational Safety

ASSOCIATION: $\quad$ Environmental Management Associates

EXPERIENCE: $\quad 23$ years

- Environmental Management Associates, Safety and Environmental Management Consultant

- Participated in Tiger Team Assessments/Technical Safety Appraisals and EH Oversight Assessments.

- Contributed to Radiological Protection Program Manuals, Industrial Hygiene Program Manuals, Environmental Protection Program Manuals, and Safety Analysis Documents and Reviews.

- Provided assistance and training related to OSHA Compliance.

- Conducted environmental liability assessments, environmental and hazardous waste permitting, and environmental remediation.

- Mason \& Hanger-Silas Mason Company, Inc.

- Departmental Scientist: Managed health physics, industrial hygiene, environmental protection and waste management programs.

- Senior Industrial Hygienist/Heaith Physicist: Responsible for issues related to health physics and industrial hygiene.

- Industrial Hygienist/Health Physicist: Responsible for fieldlevel activities involving health physics and industrial hygiene.

- Area Safety Engineer: Responsible for field-level occupational and explosives safety issues in designated plant areas.

EDUCATION: B.S., Physics, Texas Tech University 
NAME:

Linda F. Munson

AREA OF RESP: Industrial Hygiene

ASSOCIATION: $\quad$ Evergreen Innovations, Inc.

EXPERIENCE: $\quad 20$ years

- Evergreen Innovations, Inc., President

- Assisted Allied Signal Kansas City Plant in preparing a Safety Assessment Report.

- Project Manager to assist EPRI in preparing the Radwaste Desk Reference.

- Consultant to Battelle on cleanup of Three Mile Island.

- Tiger Team/Technical Safety Appraisal participant: Industrial Hygiene, Emergency Readiness, and Radiation Protection technical areas.

- Battelle's Pacific Northwest Laboratory

- Associate Section Manager, Dosimetry Technology

Section.

- Project Manager for various technical assistance programs, including cleanup of Three Mile Island and upgrade of the RMI, Inc., Health Physics Program.

- Participated in the team appraisal of six uranium mills for and with the NRC.

- Appraised emergency preparedness of the Rocky Flats Plant for DOE Headquarters.

- Observed six emergency preparedness exercises for the NRC.

- UNC Nuclear Industries

- Manager, Industrial Safety: Responsible for industrial safety, industrial hygiene, and fire protection at $\mathrm{N}$-Reactor and the associated fuel fabrication facilities.

- Managed preparation of Environmental Information Reports and license applications for various nuclear facilities.

- Evaluated decontamination alternatives for the West Valley Reprocessing Plant.

EDUCATION: M.S., Analytical Chemistry, Iowa State University

B.A., Chemistry, U.S. International University

OTHER: Short courses in Radiation Protection, Industrial Hygiene, Industrial Safety, Management Oversight Risk Tree analysis, Respiratory

Protection, Management, and Communications. 
NAME: Dennis J. Kubicki

AREA OF RESP: Fire Protection

ASSOCIATION: Office of Occupational Safety, Headquarters, Department of Energy

EXPERIENCE: $\quad 18$ years

- U.S. Department of Energy, Germantown, MD

- Senior Fire Protection Engineer

- U.S. Nuclear Regulatory Commission, Rockville, MD

- Senior Fire Protection Engineer

- National Aeronautics and Space Administration, Washington, DC

- Assistant Manager Industrial and Fire Safety

- U.S. General Services Administration, Washington, DC

- Fire Protection Engineer

- Maryland State Fire Marshal's Office, Baltimore, MD

- Fire Protection Engineer

- Insurance Services Office, Baltimore, MD

- Fire Protection Engineer

EDUCATION: M.B.A., University of Maryland

M.S., Safety, University of Southern California

B.S., Fire Protection \& Safety Engineering, Illinois Institute of Technology

OTHER: Professional Engineer, Fire Protection, State of Delaware Author of several articles concerning Fire Protection and Life Safety 
NAME: James E. Hard, P.E.

AREA OF RESP: Chemical Safety

ASSOCIATION: Nuclear Engineers and Consuitants, Inc.

EXPERIENCE: $\quad 41$ years

- Consulting Chemical Engineer

- Conduct of Operations Assessments, Pantex Plant.

- Operational Readiness Review, Savannah River HB-Line.

- Performance-based assessments, Allied Signal-Kansas City Plant.

- Safety system functional inspections at nuclear power plants.

- Advisor to DOE on nuclear safety criteria for the NPR (HWR).

- U.S. Nuclear Regulatory Commission

- Senior Resident Inspector at Prairie Island and Monticello nuclear power plants.

- Technical Assistant to NRC Commissioner and to the NRC Chairman.

- Technical Advisor to ASLBP and ASLAP legal panels.

- Senior Staff Assistant, Advisory Committee on Reactor Safeguards.

- Reactor Inspector, Midwest Region.

- General Electric Company

- Senior Reactor Engineer, plutonium-fueled test reactor.

- Reactor Supervisor, production reactors.

EDUCATION: B.S., Chemical Engineering, University of Wisconsin Graduate Studies, Nuclear Engineering, Oregon State University

OTHER: Member, American Nuclear Society, American Association for the Advancement of Science, National Society of Professional Engineers, and Minnesota Society of Professional Engineers 
APPENDIX B

EH OBSERVATIONS AND FOLLOWUP ACTIONS

B -1 



\section{EH OBSERVATIONS AND FOLLOWUP ACTIONS}

The EH OA Team identified the following Observations during this review:

Observation EHOA-SRS-RTF-01: The CRADs lack specificity in the worker safety areas.

Observation EHOA-SRS-RTF-02: Issue evaluation criteria for the DP ORR did not include consideration of matters related to worker safety.

Observation EHOA-SRS-RTF-03: The DP ORR Team specific experience in the occupational safety, industrial hygiene, and chemical safety technical areas should be strengthened.

Observation EHOA-SRS-RTF-04: The CRADs may not adequately consider process systems that may pose hazards to workers.

Observation EHOA-SRS-RTF-05: The organization of the DP ORR and the assignment of responsibilities contributed to weaknesses in the review of issues related to worker safety.

Observation EHOA-SRS-RTF-06: The DP ORR report does not reflect actual facility status at the time of the review.

A DOE memorandum from Peter N. Brush, Acting Assistant Secretary, Office of Environment, Safety and Health, to the Acting Assistant Secretary, Office of Defense Programs, transmitted this report and requested a DP response to the EH OA Observations. In addition, this memorandum requested that DP provide $E H$ with documentation verifying satisfactory closure of the following DP ORR worker safety Findings: H.2-2, M.6-2, M.7-1, M.7-2, M.7-3, M.7-4, and M.7-9. 